AperTO - Archivio Istituzionale Open Access dell'Università di Torino

First asymmetric synthesis of planar chiral [2.2]metacyclophanes

This is a pre print version of the following article:

Original Citation:

Availability:

This version is available http://hdl.handle.net/2318/1657542

since 2018-01-15T14:46:53Z

Published version:

DOI:10.1039/c3cc42275e

Terms of use:

Open Access

Anyone can freely access the full text of works made available as "Open Access". Works made available under a Creative Commons license can be used according to the terms and conditions of said license. Use of all other works requires consent of the right holder (author or publisher) if not exempted from copyright protection by the applicable law. 


\title{
First asymmetric synthesis of planar chiral [2.2]metacyclophanes $\dagger$
}

\author{
Marco Blangetti, Helge Müller-Bunz and Donal F. O'Shea*
}

\begin{abstract}
A general three step asymmetric synthesis of planar chiral [2.2]metacyclophanes utilizing selective benzylic and aryl metalations is described. The final enantioselective step is achieved using a (-)-sparteine mediated aryl metalation, following which electrophile reaction gives planar chiral cyclophanes with enantiomeric ratios (er) above 90:10.
\end{abstract}

Despite their first racemic synthesis in 1972, [2.2]metacyclophanes have failed to receive the same level of interest given to their isomeric relatives [2.2] paracyclophanes. ${ }^{1}$ Planar chiral [2.2]paracyclophanes have recently found application as promising chiral ligands and have proven a valuable contribution to the growing family of planar chiral scaffolds. ${ }^{2}$ As part of our ongoing interest in selective metalation strategies, ${ }^{3}$ we recently developed a two step racemic synthesis of planar chiral [2.2]metacyclophanes from inexpensive $m$ xylenes. ${ }^{4}$ Both transformative steps utilize LiNK metalation conditions (BuLi, KOtBu, TMP(H)) for $m$-xylene benzylic deprotonation with subsequent in situ oxidative C-C coupling. For example, the synthesis of substrate $\mathbf{1}$ can be achieved by a hetero-oxidative coupling of $m$-xylene and 1-substituted-2,4-dimethylbenzenes. ${ }^{4}$ Using LiNK conditions, a regioselective dimetalation at the thermodynamically favored benzylic positions provided $\mathbf{2}$ with in situ oxidative ring closure producing the racemic planar chiral cyclophane 3 (Scheme 1).

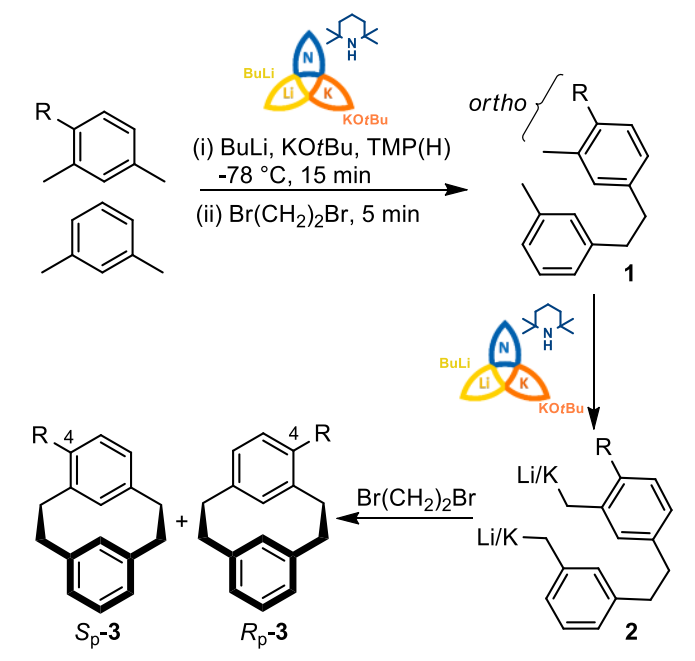

Scheme 1 Racemic synthesis of planar chiral [2.2]metacyclophanes.

A consequence of the ortho substituent pattern of the aryl ring of $\mathbf{1}$ is that the $\mathrm{R}$ substituent is positioned at C-4 position of the cyclophane, rendering it planar chiral. This two-step strategy provides the very desirable feature of a short synthetic route to these chiral scaffolds but the additional challenge of an asymmetric synthesis remains unmet. Rather than attempt the development of asymmetric ring closure of substrates $\mathbf{2}$, the success of which may vary with different R substituents, an alternative more general approach outlined in Scheme 2 was envisaged. This strategy would rely on the use of both thermodynamic and kinetic metalations to provide an asymmetric synthesis in three steps from $m$-xylenes. The first stage would exploit LiNK metalation/oxidative coupling of $m$-xylene and a 1 substituted-3,5-dimethylbenzene to provide 4 which has a meta-substitution pattern for the R substituent and methyl group (Scheme 2). Repeating the reaction sequence on $\mathbf{4}$ would produce the achiral cyclophane $\mathbf{5}$ with a substituent (R) in C-5 position. If the R substituent is capable of directing a kinetic ortho metalation, ${ }^{5}$ this would facilitate substitution at the C-4 position thereby rendering the cyclophane 6 chiral. If a metalation/electrophile trapping could be achieved in an asymmetric manner to produce 7 , then a diverse set of functional groups could be introduced via electrophile reaction. 


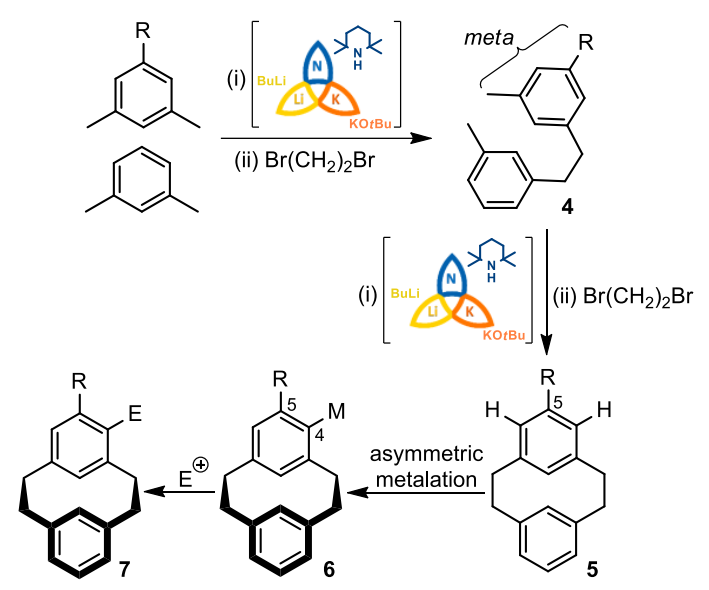

Scheme 2 Proposed asymmetric synthesis of planar chiral cyclophanes.

In this report we outline our success with this strategy to deliver the first asymmetric synthesis of planar chiral [2.2]metacyclophanes. Enantioselective lithiations have been previously reported for the synthesis of planar chiral ferrocenes, ${ }^{6}$ chromium-arenes ${ }^{7}$ and 1,11 dioxa[n]paracyclophanes. ${ }^{8}$ For this first preliminary account, two different directing groups $\mathrm{OMe}$ and $\mathrm{CON}(i \operatorname{Pr})_{2}$ were selected. The required 1,2-diarylethanes $\mathbf{8 a}$ and $\mathbf{8 b}$ were synthesized by cross-coupling of $m$-xylene with 1-methoxy-3,5-dimethylbenzene and $N, N$ diisopropyl-3,5-dimethylbenzamide respectively (Table 1, entries 1,2). To probe the effect of having both cyclophane aryl rings substituted, the bibenzyl $\mathbf{8 c}$ was generated from a homo-coupling of 1-methoxy-3,5-dimethylbenzene (entry 3). Cyclophane ring closure was achieved by dimetalation/oxidative ring closure to produce achiral C-5 substituted cyclophanes $9 \mathbf{a}$ and $\mathbf{9 b}$ and the C-5/13 dimethoxy substituted derivative $\mathbf{9 c}$ in yields from 31-42\% (Table 1). To confirm the directed ortho metalation strategy, 9a was metalated under the kinetic conditions of $\mathrm{BuLi} / \mathrm{KO} t \mathrm{Bu}$ at $-78{ }^{\circ} \mathrm{C}$ and treated with $\mathrm{CD}_{3} \mathrm{OD} .{ }^{2} \mathrm{H}$ NMR analysis showed $75 \%$ deuterium incorporated into the ortho-position of $9 \mathrm{a}-\mathrm{D}_{1}$, with no deuterium observed in the other aryl ring or the bridging methylenes (Table 1).

Table 1 Synthesis of achiral [2.2]metacyclophanes 9a-c

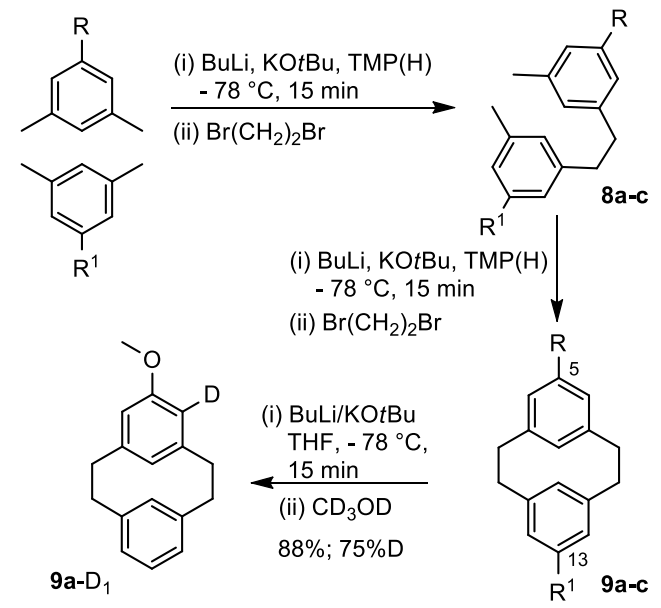

\begin{tabular}{ccccccc}
\hline Entry & $\mathrm{R}$ & $\mathrm{R}^{1}$ & $\mathbf{8}$ & Yield (\%) & $\mathbf{9}$ & Yield (\%) \\
\hline 1 & $\mathrm{MeO}$ & $\mathrm{H}$ & $\mathbf{a}$ & 40 & $\mathbf{a}$ & 42 \\
2 & $\mathrm{CON}(i \mathrm{Pr})_{2}$ & $\mathrm{H}$ & $\mathbf{b}$ & 30 & $\mathbf{b}$ & 31 \\
3 & $\mathrm{MeO}$ & $\mathrm{MeO}$ & $\mathbf{c}$ & 92 & $\mathbf{c}$ & 35
\end{tabular}

The natural product alkaloid (-)-sparteine, which can be isolated in significant quantities from papilionaceous plants, remains one of the most successful ligands for enantioselective organolithium chemistry. ${ }^{9}$ Accordingly, an optimisation study of the (-)-sparteine mediated metalation of 9a with varying alkyllithiums, solvents and temperatures was carried out with ethyl chloroformate used as electrophile (Table 2). Gratifyingly, optimal metalation conditions to produce $\mathbf{1 0 a}$ were identified as $s \mathrm{BuLi} /(-)$-sparteine in diethyl ether at $-40{ }^{\circ} \mathrm{C}$, 
which following treatment with chloroformate at $-78{ }^{\circ} \mathrm{C}$, gave the ester substituted cyclophane 11a in $65 \%$ yield and an er of $91: 9$ (Table 2 , entry 6). Using these conditions at lower temperatures $\left(-78^{\circ} \mathrm{C}\right)$ did not improve the er, whereas at higher temperatures poorer enantiodiscrimination was observed (entries $4,5,7$ ). Alternative conditions using BuLi as base or using $s$ BuLi in a hydrocarbon solvent gave very poor metalations (entries 1, 2, 8). For amido-substituted cyclophane $\mathbf{9 b}$, it was found that metalation at the lower temperature of -78 ${ }^{\circ} \mathrm{C}$ gave a better er of $85: 15$ when compared to $-40{ }^{\circ} \mathrm{C}$ (entries 11,12$)$. This is consistent with the fact that the $\mathrm{CON}(i \mathrm{Pr}) 2$ group is a stronger ortho-directing group than OMe. Encouragingly, the dimethoxy-substituted cyclophane 9c also gave an excellent er of 91:9 when reacted under identical conditions to that of $9 \mathbf{a}$ (entry 14).

Table 2 Optimisation of enantioselective metalation conditions

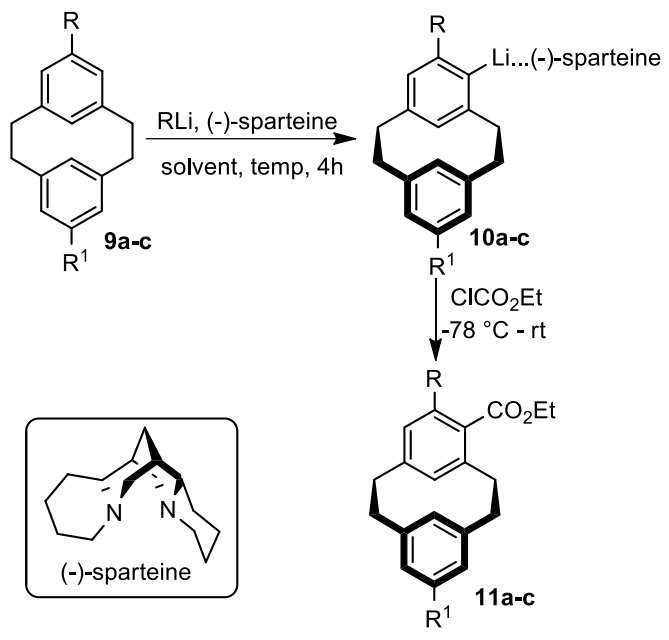

\begin{tabular}{|c|c|c|c|c|c|c|c|}
\hline Entry & 9 & $\mathrm{RLi}$ & $\mathrm{T}\left({ }^{\circ} \mathrm{C}\right)$ & Solvent & Product & $Y \operatorname{ield}(\%)$ & e.r. ${ }^{a}$ \\
\hline 1 & $\mathbf{a}$ & $\mathrm{BuLi}$ & -78 & ether & - & - & - \\
\hline 2 & $\mathbf{a}$ & $\mathrm{BuLi}$ & $\mathrm{rt}$ & ether & 11a & 15 & $72: 18$ \\
\hline 3 & $\mathbf{a}$ & $s \mathrm{BuLi}$ & $\mathrm{rt}$ & ether & 11a & 51 & $81: 19$ \\
\hline 4 & $\mathbf{a}$ & $s \mathrm{BuLi}$ & -78 & ether & 11a & 18 & $82: 18$ \\
\hline 5 & $\mathbf{a}$ & $s \mathrm{BuLi}$ & -60 & ether & 11a & 43 & $89: 11$ \\
\hline 6 & $\mathbf{a}$ & $s \mathrm{BuLi}$ & -40 & ether & 11a & 65 & $91: 9$ \\
\hline 7 & $\mathbf{a}$ & $s \mathrm{BuLi}$ & -20 & ether & 11a & 58 & $85: 15$ \\
\hline 8 & $\mathbf{a}$ & $s \mathrm{BuLi}$ & 0 & heptane & 11a & - & - \\
\hline 9 & $\mathbf{b}$ & $\mathrm{BuLi}$ & -40 & ether & - & - & - \\
\hline 10 & $\mathbf{b}$ & $s \mathrm{BuLi}$ & 0 & heptane & - & - & - \\
\hline 11 & $\mathbf{b}$ & $s \mathrm{BuLi}$ & -40 & ether & 11b & 73 & $74: 26$ \\
\hline 12 & $\mathbf{b}$ & $s \mathrm{BuLi}$ & -78 & ether & 11b & 76 & $85: 15$ \\
\hline 13 & c & $\mathrm{BuLi}$ & -78 & ether & - & - & - \\
\hline 14 & c & $s \mathrm{BuLi}$ & -40 & ether & $11 \mathrm{c}$ & 46 & 91:9 \\
\hline
\end{tabular}

a compared to racemic samples generated using (i) BuLi/PMDTA (ii) $\mathrm{ClCO}_{2} \mathrm{Et}$.

Assignment of the absolute configuration of the predominant enantiomer of 11a was carried out using X-ray crystallography. The major isomer was purified by chiral HPLC and crystallized by the slow evaporation of a diethyl ether solution. Single crystal diffraction analysis showed it crystallized in the P2 1 space group with absolute configuration assigned as $R_{\mathrm{p}}$ (Fig. 1 ). ${ }^{10 \mathrm{a}}$ 




Fig. 1 Single molecule structure of $R_{\mathrm{p}} \mathbf{- 1 1 a}$. Thermal ellipsoids drawn at the $50 \%$ probability level.

While 11a had the expected structural features of a [2.2]metacyclophane ring, ${ }^{11}$ it was interesting to observe that the $\mathrm{C} 4 / 5$ di-substitution pattern caused the ester group to rotate by $86.1^{\circ}$ to the plane of the aromatic cyclophane ring. This contrasts to the mono $\mathrm{C}-4$ carboxy substituted cyclophane in which the torsion angle is only $16.6^{\circ 4 \mathrm{~b}}$ and can be rationalised by electronic repulsion between the oxygen atoms of the ester and ether groups. Ester saponification of a rac-11a was readily achieved with $\mathrm{KOH}$ in 2-propanol ${ }^{12}$ to give the $\mathrm{C} 4 / \mathrm{C} 5$ $\mathrm{CO}_{2} \mathrm{H} / \mathrm{OMe}$ substituted cyclophane 11d which was analysed by X-ray crystallography. ${ }^{10 \mathrm{~b}}$ As in the ester derivative above, the carboxylate group has a large torsion angle with respect to the aryl ring of $70.0^{\circ}$. Unusually, in the extended structure, the carboxylates of 11d are hydrogen bonded to a neighbouring molecule by a single hydrogen bonding motif with an O...O distance of $2.63 \dot{A}$ as shown in Fig 2. This gives rise to a catemeric one-dimensional hydrogen bonded network in which neighbouring molecules of 11d associate with each other via a two-point hydrogen bonding contact in a head-to-head staggered manner. ${ }^{13}$ This contrasts with the mono-C4 carboxy substituted cyclophane which crystallized as the more common centrosymmetric carboxylate dimer. ${ }^{4 \mathrm{~b}}$

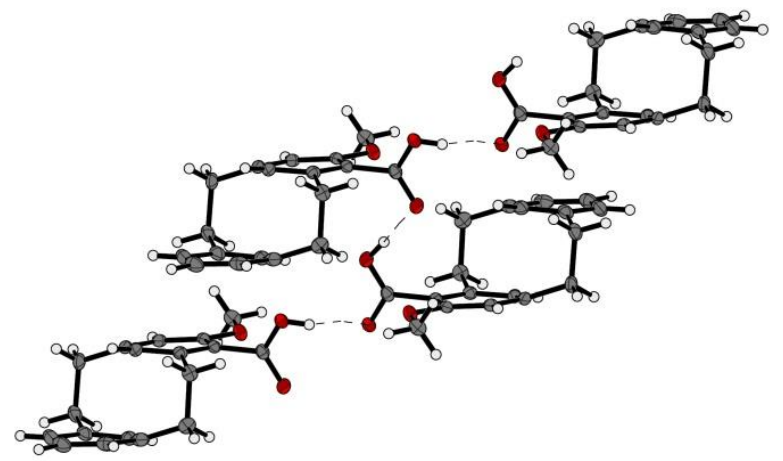

Fig. $2 \mathrm{X}$-Ray structure of $\mathrm{rac}-\mathbf{1 1 d}\left(\mathrm{P} 2_{1} / \mathrm{c}\right.$ space group). Thermal ellipsoids drawn at the $50 \%$ probability level $\left(\mathrm{CO}_{2} \mathrm{H}\right.$ group disorder neglected).

The generality of this synthetic strategy was illustrated by reaction of the enantioselectively metalated cyclophanes 10a-c with the series of electrophiles, DMF, $\mathrm{I}_{2}$, diethyl chlorophosphate and chlorodiphenylphosphine (Table 3 ). In each case the reaction was successful with ers the same or slightly better than that obtained for ethyl chloroformate. This is indicative of the metalation reaction being the enantiodiscriminating step with the er of the product not being overly electrophile dependent.

Table 3 Electrophile reaction with 10a-c

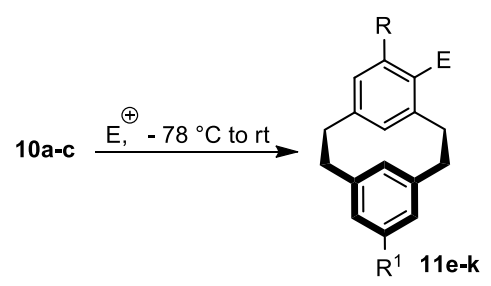




\begin{tabular}{ccccccc}
\hline Entry & $\mathbf{1 0}$ & $\mathrm{E}^{\oplus}$ & $\mathbf{1 1}$ & $\mathrm{E}$ & Yield (\%) & e.r. \\
\hline 1 & $\mathbf{a}$ & $\mathrm{DMF}$ & $\mathbf{e}$ & $\mathrm{CHO}$ & 68 & $91: 9$ \\
2 & $\mathbf{a}$ & $\mathrm{I}_{2}$ & $\mathbf{f}$ & $\mathrm{I}$ & 59 & $93: 7$ \\
3 & $\mathbf{a}$ & $\mathrm{ClP}(\mathrm{O})(\mathrm{OEt})_{2}$ & $\mathbf{g}$ & $\mathrm{P}(\mathrm{O})(\mathrm{OEt})_{2}$ & 58 & $95: 5$ \\
4 & $\mathbf{a}$ & $\mathrm{ClP}(\mathrm{Ph})_{2}$ & $\mathbf{h}$ & $\mathrm{P}(\mathrm{O}) \mathrm{Ph}_{2}$ & 69 & $95: 5^{\mathrm{a}}$ \\
5 & $\mathbf{b}$ & $\mathrm{DMF}$ & $\mathbf{i}$ & $\mathrm{CHO}$ & 59 & $84: 16$ \\
6 & $\mathbf{c}$ & $\mathrm{ClP}(\mathrm{O})(\mathrm{OEt})_{2}$ & $\mathbf{j}$ & $\mathrm{P}(\mathrm{O})(\mathrm{OEt})_{2}$ & 40 & $90: 10$ \\
7 & $\mathbf{c}$ & $\mathrm{DMF}$ & $\mathbf{k}$ & $\mathrm{CHO}$ & 58 & $91: 9$
\end{tabular}

${ }^{a}$ oxidation occurred on work up.

Finally, the racemisation barriers $\left(\Delta \mathrm{G}^{*}\right)$ of 11a-c were determined as $141.6,134.5$ and $135.4 \mathrm{~kJ} / \mathrm{mol}$ respectively, on the basis of the absolute rate equation, by experimentally following their racemisation in NMP at $453 \mathrm{~K}$. These values are sufficiently high to encourage future investigation of [2.2]metacyclophanes as potential planar chiral catalysts and ligands.

\section{Conclusions}

In summary, the first general enantioselective synthesis of planar chiral [2.2]metacyclophanes has been accomplished. The structural features of the C4/C5 substituted derivatives identified by X-ray analysis may assist in predictive design of catalysts and ligands. The facile three step synthesis and relatively high inversion barrier to racemisation indicates their potential as planar chiral catalysts and ligands, which to date has not been explored. We thank the European Research Association ERA-Chemistry and the Irish Research Council (IRC) for financial support.

\section{Notes and references}

School of Chemistry \& Chemical Biology, University College Dublin, Belfield, Dublin 4, Ireland; Tel: 353-1-7162425; E-mail: donal.f.oshea@ ucd.ie. $\dagger$ Electronic Supplementary Information (ESI) available: Experimental procedures, spectral data, HPLC, NMR spectra for all new compounds racemisation data for 11a-c.

1 B. Kainradl, E. Langer, H. Lehner and K. Schlögl, Liebigs Ann. Chem. 1972, 766, 16.

2. (a) J.F. Schneider, R. Fröhlich and J. Paradies, Isr. J. Chem. 2012, 52, 76; (b) J. Paradies, Synthesis, 2011, 23, 3749; (b) S.E. Gibson and J.D. Knight, Org. Biomol. Chem. 2003, 1, 1256; (c) S. Bräse, S. Dahmen, S. Höfener, F. Lauterwasser, M. Kreis and R.E. Ziegert, Synlett 2004, 2647; (d) R. Gleiter, H. Hopf, Modern Cyclophane Chemistry, Wiley-VCH, Weinheim, 2004; (e) P.J. Pye, K. Rossen, R.A. Reamer, N.N. Tsou, R.P. Volante and P.J. Reider, J. Am. Chem. Soc. 1997, 119, 6207.

3. (a) P. Fleming and D.F. O'Shea, J. Am. Chem. Soc. 2011, 133, 1698. (b) M. Blangetti, P. Fleming and D.F. O'Shea, J. Org. Chem. 2012, 77, 2870.

4. (a) M. Blangetti, P. Fleming and D.F. O'Shea, Beilstein J. Org. Chem. 2011, 7, 1249. (b) M. Blangetti, H.M. Bunz and D.F. O'Shea, Tetrahedron, 2013, http://dx.doi.org/10.1016/j.tet.2013.03.076.

5. M. C. Whisler, S. MacNeil, V. Snieckus and Peter Beak, Angew. Chem. Int. Ed. 2004, 43, 2206.

6. W.-P. Deng, V. Snieckus and C. Metallinos, Chiral Ferrocenes in Asymmetric Catalysis, Wiley-VCH, Weinheim, 2010.

7. S.E. Gibson and H. Ibrahim, Chem. Commun. 2002, 2465.

8. K. Kanda, K. Endo and T. Shibata, Org. Lett. 2010, 12, 1980.

9. (a) P. Beak, A. Basu, D.J. Gallagher, Y.S. Park and S. Thayumanavan, Acc. Chem. Res. 1996, 29, 2283; (b) D. Hoppe and T. Hense, Angew. Chem. Int. Ed. 1997, 36, 2282.

10. (a) CCDC $920659\left(R_{\mathrm{p}}-\mathbf{1 1 a}\right)$; (b) CCDC 920658 ( $\left.\mathrm{rac}-\mathbf{1 1 d}\right)$.

11. For example, step-wise anti-confirmation of aryl rings which have significant distortion from planarity $\left(8.3^{\circ}\right.$ and $\left.7.2^{\circ}\right)$ and inter-annular distance of $2.64 \dot{\mathrm{A}}$

12. Saponification of $R_{\mathrm{p}} \mathbf{- 1 1 a}$ was also achievable under these conditions without racemisation.

13. For other catemer examples see; (a) P. Sanphui, G. Bolla, U. Das, A.K. Mukherjee and A. Nangia, CrystEngComm, 2013, 15, 34; (b) D. Das and G.R. Desiraju, Chem. Asian. J. 2006, 1-2, 231; (c) K. Kobayashi, T. Shirasaka, E. Horn and N. Furukawa, Tetrahedron Lett., $1999,40,8883$. 